\title{
The significance of hyponatraemia in liver failure
}

\author{
H. RING-LARSEN \\ M.D. \\ Medical Department A, Division of Hepatology, Rigshospitalet, University Hospital, \\ Copenhagen, Denmark
}

\begin{abstract}
Summary
It is possible by means of peritoneal dialysis to correct hyponatraemia occurring in liver failure. The normalization is not, however, attended by any apparent improvement in liver function, hepatic encephalopathy or renal function. Likewise correction of the serum ammonia level did not improve the clinical picture.

A correction of the extracellular ion concentration and a possible more normal intracellular composition achieved by peritoneal dialysis may thus eliminate one life-threatening factor in severe liver failure. However, this does not seem to improve the chances of survival of the patients.
\end{abstract}

IN spite of the fact that the salt and water intake varies considerably, the serum sodium concentration in normal individuals remains extremely constant between 135 and $145 \mathrm{mEq} / \mathrm{l}$. The major part of the osmotically active solutes in the serum are the salts of sodium, and since the body preserves the total solute concentration in the serum within narrow limits of some $275-290 \mathrm{mmol} / \mathrm{kg}$ water, the serum sodium concentration is kept fairly constant. A slight rise of $1-2 \%$ in effective total solute concentration is able to stimulate maximal release of $\mathrm{ADH}$ as shown by Verney. This is probably the best illustration of the effectiveness of body solute and water regulation.

Except for a few special conditions, i.e. uraemia, hyperglycaemia and hyperlipidaemia, the serum sodium concentration reflects the total solute concentration of serum, which can be calculated approximately by doubling the serum sodium concentration. This is also true for patients with liver diseases with sodium and water retention. The serum sodium concentration serves as an index of the concentration of water in the body fluids, since the interstitial fluid is simply an ultrafiltrate of the serum, with the same concentration of small solutes except for the small differences dictated by the Donnan effect, and since the tonicity of the intracellular fluids is the same as that of the extracellular fluids. The greater part of the total exchangeable sodium is located in the extracellular compartments. Since the volume of the extra- cellular fluid depends on the quantity of sodium there, the state of hydration reflecting the extracellular fluid volume is a result of the extracellular content of sodium.

With serum sodium concentrations below 135 $\mathrm{mEq} / \mathrm{l}$, hyponatraemia is frequent in patients with liver disease. Serum sodium concentration in these cases, as in other clinical conditions with hyponatraemia, is a good prognostic index. Values below $100 \mathrm{mEq} / \mathrm{l}$ are usually not compatible with life. In conditions with hyponatraemia, the symptoms generated by the low serum sodium and those of the underlying disease are difficult to separate. The symptoms of hyponatraemia, i.e. difficulty in cont centrating, anorexia, headache, apathy, nausex vomiting and perhaps convulsions are all symptoms which may be found in hepatic coma or precoma and normal serum sodium concentration. However, from clinical observations of the hyponatraemic state in other diseases, it is probably justifiable to expect the known symptoms in liver diseases to result from dilution.

Hyponatraemia occurs clinically in two different sets of circumstances in liver disease, and always reflects relative excess of water over solutes in the body.

The term 'depletional' refers to the total exchangeable sodium which in this condition is below the normal amount. This type of hyponatraemia with a net deficit of total exchangeable sodium and contracted extracellular fluid volume is rarely seen in patients with liver diseases. When it is, it is most often associated with vigorous treatment with potent diuretics. Often this is accompanied by grave hypokalaemia in spite of supplementation of potassium salts.

In the dilutional type of hyponatraemia, which is frequent in patients with cirrhosis of the liver, the serum sodium concentration is often less than 120 $\mathrm{mEq} / \mathrm{l}$, while this low level is not usually observed in hyponatraemia due to sodium depletion.

Since the study of Hecker and Sherlock (1956), hyponatraemia and overhydration have been regarded as preceding symptoms of functional renal failure in cirrhosis. Because of this, and because 
TABLE

\begin{tabular}{lccc}
\hline & Serum-Na & $\begin{array}{c}\text { Total exch. } \\
\mathrm{Na}^{+}\end{array}$ & Body $\mathrm{H}_{2} \mathrm{O}$ \\
\hline $\begin{array}{l}\text { Depletional } \\
\text { Dilutional }\end{array}$ & Low & Low & Low \\
\hline
\end{tabular}

hyponatraemia shares symptoms with hepatic coma, a study was undertaken in order to observe the effect of correcting the serum sodium by peritoneal dialysis in patients with liver failure complicated by hyponatraemia (Ring-Larsen, Clausen and Ranek, 1972).

Seventeen patients, aged from 12 to 69 years, were chosen. All had extremely low serum sodium, advanced liver failure due to acute liver disease, or acute exacerbation in a chronic liver illness, and were treated with peritoneal dialysis. The patients had the following diagnoses: five cryptogenic cirrhosis; six alcoholic cirrhosis; two viral hepatitis; two halothane hepatitis; one common duct stone complicated with thrombosis of the portal vein. All but one had signs of hepatic encephalopathy and were in coma or precoma. All but two had clinical signs of ascites, usually gross. No patient had a preexisting history of renal disease. On admission, three patients had mild urinary infection easily controlled by chemotherapy. No autopsy revealed tubular necrosis.

At the time of dialysis four patients had normal urine output and normal serum creatinine, five had normal diuresis but additional azotaemia (serum creatinine $>1.3 \mathrm{mg} \%$ ) and eight had additional azotaemia as well as oliguria $(<500 \mathrm{ml} / 24 \mathrm{~h})$. In these three groups of patients the serum sodium was uniformly extremely low. Peritoneal dialysis was started when the serum sodium was below $125 \mathrm{mEq} / \mathrm{l}$. Two litres of ascitic fluid were removed initially, and simultaneously $200 \mathrm{ml}$ of $20 \%$ of human albumin were given intravenously. The dialysing solution was preheated to $37^{\circ} \mathrm{C}$. The solution contained $140 \mathrm{mEq} \mathrm{Na}{ }^{+}, 4$ $\mathrm{mEq} \mathrm{K}+1.8 \mathrm{mEq} \mathrm{Mg}{ }^{++}, 45 \mathrm{mEq}$ lactate, and $1.5 \%$ glucose $(372 \mathrm{mmol} / \mathrm{l})$. Every cycle of 21 lasted for $1 \mathrm{hr}$. Total dialysing time averaged $48 \mathrm{hr}$. Protein loss was continuously measured, and human albumin was given i.v. to compensate for the loss. In patients with gross ascites, the target was a weight loss of approximately $4 \mathrm{~kg}$ /day which was not always achieved. Central venous pressure was monitored to avoid overloading. Patients with a prothrombin time below $20 \%$ of normal received fresh frozen plasma to prevent haemorrhage during insertion of the abdominal catheter.

Serum sodium averaged $119 \mathrm{mEq} / \mathrm{l}$ before dialysis. A significant rise was observed during dialysis, and the mean value remained above $130 \mathrm{mEq} / \mathrm{l}$ for the week following dialysis.

The 24-hr urinary sodium was extremely low in all but one patient and did not increase following dialysis except in the one patient who also failed to show a greatly increased diuresis.

Just before peritoneal dialysis, five patients had hyperkalaemia and two had hypokalaemia. This was corrected in all patients at the start of dialysis. The values decreased rapidly, during continued dialysis, in twelve patients to a level below that of the concentration of the dialysing solution. Samples of the dialysate showed that the concentration had decreased below the initial level of $4 \mathrm{mEq} / \mathrm{l}$, indicating intracellular entry of this ion.

A significant rise in the mean value of the standard bicarbonate was observed at the termination of dialysis. No consistent pattern was seen in the diuresis during or immediately after the dialysis. Serum ammonia was determined in five patients immediately before and after dialysis. The concentration changed from a mean value of $125 \mu \mathrm{mol} / \mathrm{l}$ to a mean value of $75 \mu \mathrm{mol} / \mathrm{l}$. No change in coma grade was observed in immediate relation to peritoneal dialysis.

Three patients survived for more than 6 months. Eight died 4-17 days after dialysis, and six died during the procedure. The survival time is correlated with the diuresis $(P<0.05)$ but not with the 24-h sodium output, nor with the serum sodium concentration before dialysis. The most frequent causes of death were hepatic coma and gastrointestinal bleeding. Among the six patients dying during dialysis, two died from complications in the procedure, i.e. haemorrhage from the abdominal wound when the catheter was removed, and pulmonary oedema.

The poor prognosis in pronounced hyponatraemia is confirmed in this series, the mortality rate being $82 \%$.

\section{References}

Hecker, R. \& Sherlock, S. (1956) Electrolyte and circulatory changes in terminal liver failure. Lancet, ii, 1121.

Ring-larsen, H., Clausen, E. \& Ranek, L. (1972) Peritoneal dialysis in hyponatraemia due to liver failure. Scandinavian Journal of Gastroenterology, 8, 33.

Verney, E.B. (1947) Croonian Lecture: Antidiuretic hormone and factors which determine its release. Proceedings of the Royal Society, London (B), 135, 25. 